\title{
Ambivalence, Avoidance, and Appeal: Alliterative Aspects of Anglo Anthroponyms
}

\author{
Stephen J. Bush (D) \\ NDM Experimental Medicine, University of Oxford, Oxford, UK
}

In several countries, one of the most pronounced trends in contemporary baby naming is selecting a comparatively uncommon name. Nevertheless, although a well-documented phenomenon, studies of uncommon name use are often limited to forenames. This study analyses approximately 22 million full names from England and 1 million from Wales, given between 1838 and 2014. It addresses the hypothesis that, consistent with the contemporary desire to choose an uncommon name, alliterative names uncommon by definition - would become increasingly popular. More broadly, this study charts the long-term trends in alliterative naming over time. In both England and Wales, this pattern is consistent with a random expectation for much of the $19^{\text {th }}$ century but declines significantly throughout the $20^{\text {th }}$ century to its lowest use in the 1970 s. This trend reverses towards the end of the $20^{\text {th }}$ century, with alliterative naming becoming more common in contemporary records. These three aspects of alliterative name use are thematically referred to as 'ambivalence', 'avoidance' and 'appeal'; and may reflect changing attitudes towards alliterative naming. The relatively renewed appeal of alliterative names towards the end of the $2 \mathrm{O}^{\text {th }}$ century complements previous research on the preponderance of uncommon names and the contemporary 'need for uniqueness' in naming.

KEYWORDS alliteration, anthroponym, baby names, Anglo, England

\section{Introduction}

In several countries, one of the most pronounced trends in contemporary baby naming is to choose a comparatively uncommon name. This has previously been 
observed in US American (Twenge, Abebe, and Campbell 2010; Twenge, Dawson, and Campbell 2016), British (Bush, Powell-Smith, and Freeman 2018), Chinese (Cai et al. 20I8), German (Gerhards and Hackenbroch 2000), and Japanese (Ogihara et al. 2015) datasets which, taken together, suggest an increasing 'need for uniqueness', a collective behaviour conceptualised as "a positive striving for abnormality relative to other people" (Snyder and Fromkin I977). This preference for 'abnormality' must by necessity occur within, although towards the fringes of, both culturally acceptable and legally permissible limits. It is not always easy to coin a distinctive name, despite the evident desire for it.

This paper hypothesises that, consistent with these contemporary trends, alliterative names will become increasingly popular. More formally, alliteration, the repetition of word-initial sounds, is a poetic, rhetorical and mnemonic device that can add a performative element to names that are principally referential. Phonological patterns, including alliteration, assonance, and rhythm, are known to aid the recall of multi-word expressions (Boers and Lindstromberg 2005; Boers, Lindstromberg, and Eyckmans 20I4), for instance in poetry (Lea et al. 2008). Assuming a corollary of 'uniqueness' is the desire to be more memorable, it follows that alliterative personal names - one's name being a multi-word expression - could more readily be brought to mind than those which are not. It is therefore reasonable to believe that the choice of an alliterative name meets a 'need for uniqueness' as the first name is by definition influenced by a surname about which there is often little choice involved. In the UK, surnames are commonly either one of the parents' surnames, conventionally the father's; or a double-barrelled surname, combining both. Nevertheless, this hypothesis is not easy to test. Many English-language name datasets are often, due to privacy restrictions, limited to first names, with the full name (i.e., including middle names and surnames) unavailable. ${ }^{\mathrm{I}}$ In such circumstances, trends in alliterative naming over time cannot readily be identified.

In this study, alliterative names are considered to be, at minimum, two-part names: those where the first and family name begin with the same initial character, such as Simon Smith, irrespective of any middle names. An extension of this definition is the 'triply alliterative' name, such as Simon Samuel Smith, wherein the forename, (only) middle name, and surname begin with the same initial character. Alliteration in this study is restricted to 'external alliteration', which refers to the point of similarity between two or more connected names, such as a forename and surname. This is in contrast to 'internal alliteration', which refers to internally-repetitive characters within the same forename, such as Barbara, or between name-themes in compound names (as seen, for instance, in Old Germanic name formation (Kangro 2006)). This is a pragmatic definition that identifies alliteration on the basis of character, not sound, and makes the simplifying assumption that individual characters correspond to identical sounds.

This study illustrates patterns of alliterative English baby naming from 1838 to 2014 by making use of a full name dataset of $23,468,892$ records. This 
dataset was compiled primarily from the 'local BMD' (births, marriages and deaths) registers of England and detailed in previous publications (Bush 2019; Bush, Powell-Smith, and Freeman 2018). Three patterns of alliterative name use are identified. Thematically, they are referred to as 'ambivalence', 'avoidance' and 'appeal'. These uses reflect possible attitudes towards alliteration characteristic of particular time periods. From I 838 until the mid-20 ${ }^{\text {th }}$ century, the proportion of alliterative birth records is largely consistent with a random expectation. At its simplest, for any given English-language surname, there is a I in 26 chance that the first name will have the same letter, and so a random (but naïve) expectation for the proportion of alliterative birth records in a given year is $3.8 \%$. This baseline percentage could be interpreted as suggesting a degree of ambivalence towards alliteration: that there is neither a particular preference for, nor aversion to, alliterative naming in general. Deviations from this baseline may be interpreted as relative aversion or relative appeal, and can reflect changes either in the associations perceived of an alliterative name or (more likely) simply in the pool of names from which it is possible to draw. When adjusting for the latter, the observed proportion of alliterative birth records per year does not significantly differ from the expected proportion until the mid$20^{\text {th }}$ century (i.e., suggesting 'ambivalence' towards alliteration), whereupon the observed proportion falls below expectations ('avoidance') but, from the I980s to the present day, rises again to approach, and occasionally exceed, the expected ('appeal'). The latter observation complements previous research on the preponderance of uncommon names and is discussed in the context of a contemporary 'need for uniqueness' in personal naming.

\section{Materials and Methods}

\section{Source of Name Data}

In England and Wales, birth, marriage, and death (BMD) registration began in July I 837. BMD records were obtained from the 'UK local BMD' project (http:// www.ukbmd.org.uk/local), a volunteer-led effort to transcribe the local indices of the UK BMD registers for digital preservation. These local indices were originally sent to a central body, the General Register Office in London, for compilation into a national catalogue; this catalogue is not publicly available. Birth records spanning the complete years I 838-20I4 were downloaded in September 2016 as part of a previous study describing the application of network methods to onomastic data (Bush, Powell-Smith, and Freeman 20I8). These records were then updated in January 2018 for a study describing the re-use of birth records in response to child bereavement (Bush 2019). Employing the data used for the latter, 23,468,892 birth records were parsed for the present study. ${ }^{2}$

These birth records were collated from ten different locales, nine from England and one from Wales, each transcribed by different groups of volunteers, ostensibly from the same area (the city of Bath; the counties of Berkshire, 
Cheshire, Cumbria, Lancashire, Staffordshire, Wiltshire and Yorkshire and the West Midlands; and the more broadly defined region of North Wales). Accordingly, the data is non-uniform both in terms of the number of records per region and the depth of coverage over time. The records are assumed to be unbiased, being transcribed from birth registers that were filled on an ad hoc basis, and of sufficient breadth as to represent English and Welsh naming trends over time. The number of records per region and the years and regions covered are detailed in Supplementary material Table $\mathrm{I},{ }^{3}$ with the methods of data cleaning and curation described in the following resource: (Bush, Powell-Smith, and Freeman 20I8). Data cleaning comprised the correction of typographical errors, removal of uninformative entries, and expansion of abbreviations, such as Wm for William. The available fields for each birth record were the first name, middle name(s) and surname, mother's pre-marriage surname (if applicable), year of birth, sub-district of the region in which the birth was registered, and identification number. This dataset approximates 130,000 to 230,000 records per year from I 838 to $1950 ; 25,000$ to I00,000 records per year from I95I to 2000; and 5000 to I 5,000 records per year from 200 I to 2014 .

\section{Observed and Expected Alliterative Naming}

For each alliterative two-letter combination (the first name and surname both beginning with A, then BB, CC, and so on), observed/expected ratios were calculated to account for the fact that the pool of names from which it is possible to draw in a given year is non-uniform. For each year, the expected number of alliterative records in, for example, the letter A equals the percentage of records with a first name beginning with $\mathrm{A} \times$ the total number of records with a surname beginning with $\mathrm{A}$. The null hypothesis that the observed and expected numbers of alliterative birth records are drawn from the same continuous distribution was assessed using a two-sample Kolmogorov-Smirnov test. The significance of any difference between groups (observed and expected records within certain time periods) was assessed using a chi-squared test. All statistical analyses were conducted in R v3.6.I (R Core Team 2019).

\section{Results}

\section{Trends in Alliterative Naming: Ambivalence, Avoidance, and Appeal}

Trends in alliterative naming in England and Wales were examined using a dataset of $23,468,892$ birth records spanning I77years, from I 838 to 20I4, of which $\mathrm{I}, \mathrm{I} 70,606$ (5\%) were alliterative, having the first and family names starting with the same character (irrespective of any middle name). Only 10,798 records, $0.05 \%$ of the total, were 'triply alliterative', with the first, middle, and family names starting with the same character. The proportion of alliterative birth records per year is shown in Figure I and summarised in Supplementary 


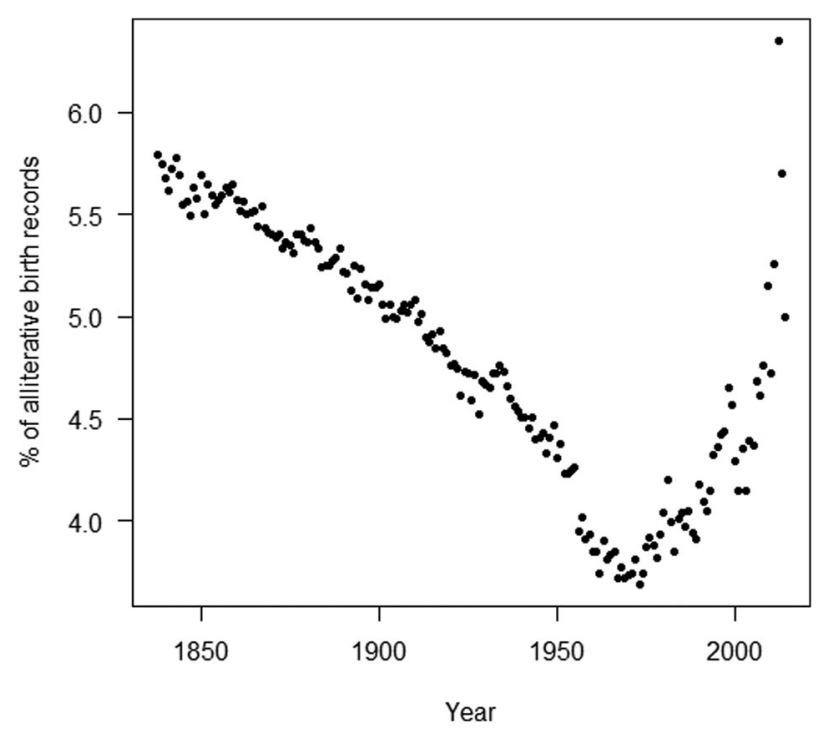

FIGURE 1. Proportion of alliterative birth records per year. Raw data for this figure is available as Supplementary material Table 2.

material Table 2. The corpus of alliterative names is given in Supplementary material Table 3. Broadly speaking, alliterative naming declines steadily throughout the $19^{\text {th }}$ and $20^{\text {th }}$ centuries, reaching its lowest point, approximately $3.8 \%$, in the mid-I970s. From the I980s onwards, however, this trend reverses with an increase in alliterative naming apparent, rising to approximately $5 \%$ of records per year from the year 2000 .

While the initial decline in alliterative name use (see Figure I) is pronounced, it is likely coincidental, reflecting the expansion of the name pool rather than (for instance) a negative perception to alliterative naming. This might be because, as the $20^{\text {th }}$ century progressed, a far greater number of names would have entered the cultural milieu, diversifying the pool of forenames from which to draw. With an expanding number of forenames to choose from (or create), and assuming free choice, the proportion of alliterative names in a random sample of English-language names is expected to be $3.8 \%$ (i.e., I in 26). A greater percentage of alliterative names are observed throughout much of the $19^{\text {th }}$ and $20^{\text {th }}$ centuries (see Figure I) likely because, historically, there was both a smaller number of forenames to choose from and relatively reduced social freedom to follow fashion instead of tradition. As such, a minority of names accounted for the majority of birth records. The size of this majority has declined over time and no longer exists in the present day. The proportion of births registered with one of the top ro most common female or male names has decreased from $>$ $70 \%$ in 1850 to $<20 \%$ by 2010 (Figure 2 ).

What this means in practice is that common surnames that begin with the same initial as a particularly popular forename would be disproportionately represented in the historical records of this dataset. Towards the present day, this 


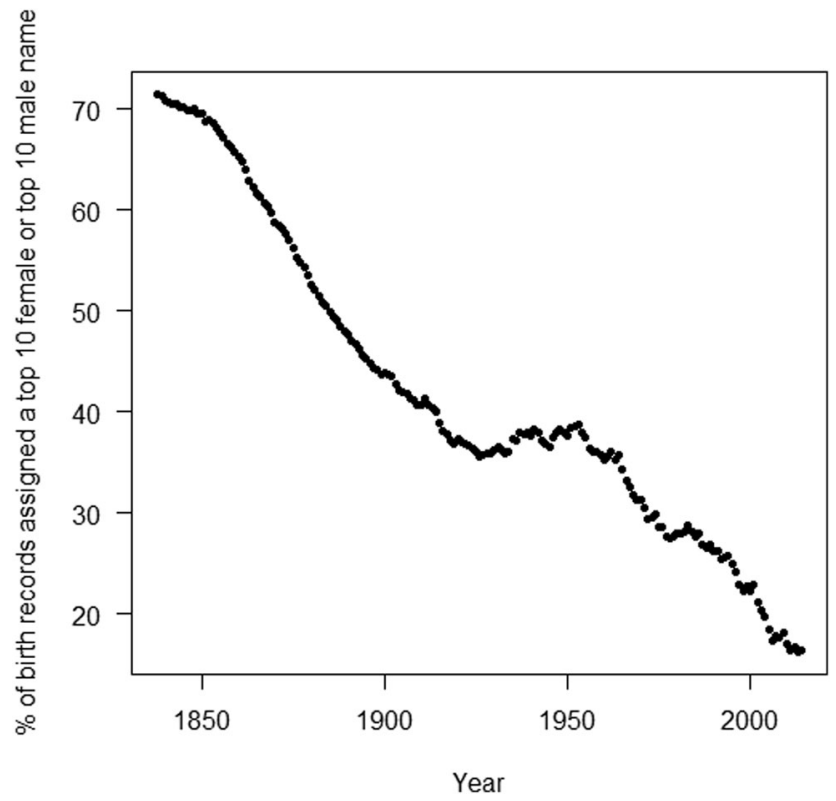

FigURE 2. Proportion of birth records per year assigned to one of the top 10 most common names (male or female). Raw data for this figure is available as Supplementary material Table 2.

would become less pronounced as the popularity of any given forename declines. In this respect, the initial downward trend in Figure I can be interpreted as a consequence of the trend shown in Figure 2, an argument developed in more detail below. If considering the top 20 surnames in the dataset, these collectively represent 2,860,435 birth records, I $2 \%$ of the total. These surnames are, in order, Jones, Smith, Williams, Taylor, Roberts, Davies, Hughes, Evans, Brown, Jobnson, Jackson, Robinson, Wilson, Wood, Walker, Harrison, Edwards, Thompson, and Wright. If we assume an approximately equal number of births per year with each surname, then popular first names with the same letter as a common surname would account for a disproportionate number of alliterative birth records. Consistent with this finding, the most frequently occurring alliterative names in the dataset were John Jones (27,404 total records) and William Williams (I I,63 I records). John and William are the two most common male names overall, and were historically especially prevalent (Bush, Powell-Smith, and Freeman 2018). The most common alliterative female names were Jane Jones ( 8738 records) and Sarah Smith (6276 records), in both cases supported by relatively fewer records. This is likely because the pool of female names is generally larger than that of male names. ${ }^{4}$ For the same reason, the most common 'triply alliterative' female names were Alice Ann Ashworth and Elizabeth Ellen Evans, albeit with only 9I and 54 records, respectively. The most common triply alliterative male name was John James Jones, at $\mathrm{I} 30$ records, followed by John James Jackson, John James Johnson, and John Joseph Jones at 87, 60, and 57 records, respectively. 
To account for the distorting effect popular first names would have upon the total number of alliterative records, we calculated observed/expected ratios for each alliterative two-letter combination (see Materials and Methods). By plotting the distribution of these ratios over time, a clearer overview was obtained of trends in alliterative naming. These trends are illustrated in Figure 3 and summarised in Supplementary material Table 4. In Figure 3, the boxes represent the interquartile range of the set of ratios, with midlines representing the median. Upper and lower whiskers extend, respectively, to the largest and smallest values no further than I.5 $\mathrm{X}$ the interquartile range. Data beyond the ends of each whisker are outliers and plotted individually. The lower black line denotes $y=\mathrm{I}$, where the observed number of alliterative names equals the expected. Note that only letter combinations observed in > Ioo birth records are included in this figure. As fewer records are available for the years 200I-20I4 (see Materials and Methods), this threshold excludes much of the data within this period. Of the 364 two-letter combinations within this period (26 combinations I4 years), observed/expected ratios were only available for eight, i.e., $2 \%$ of the total. Raw data for this figure is available as Supplementary material Table 4. The steady decline in the percentage of alliterative birth records from the I840s to the I920s, as illustrated in Figure I, can now be seen as consistent with the changing composition of the name pool. Figure 3 shows that across this time period, the observed/expected ratio approximates $\mathrm{I}$. The null hypothesis that the observed and expected numbers of alliterative birth records were drawn from the same continuous distribution was assessed using a two-sample KolmogorovSmirnov test, and was not rejected $(p=0.504)$. The Kolmogorov-Smirnov test compared the distributions of observed and expected counts from the years I 838 to I920, each distribution containing I 234 data points. There were six prominent $19^{\text {th }}$ century outliers in Figure I (the years I 843 , I 85 I, I 854 , I 856 , I 857 , and I867, where observed/expected ratios $>$ I.4) each of which could be associated with the letter D (see Supplementary material Table 4). We can only speculate as to why this is the case. Forenames that are especially common would increase the number of expected alliterative records for that letter, so increasing the number of observed alliterative records required to constitute an outlying observed/expected ratio. As Figure 2 illustrates, the ten most common male and female names between I 850 and I 870 account for a per-year average of $65 \%$ of the registered births, although neither begin with the letter $\mathrm{D}$ (the most popular names within this period are, in order, John, William, Thomas, James, George, Joseph, Henry, Charles, Robert, and Samuel for males, and Mary, Elizabeth, Sarah, Ann, Margaret, Jane, Alice, Ellen, Hannah, and Emma for females). Names not recorded in the top ro are not necessarily uncommon. It is plausible that names in the top 50, for example, are being paired with a sufficient number of surnames so as to produce an outlier. For instance, in $\mathrm{I} 85 \mathrm{I}$, the fourteenth most common male name was David. An alternative explanation is that names beginning with $\mathrm{D}$ are disproportionately found in particular ethnic or regional subgroups within the wider dataset. In this case, the most plausible 


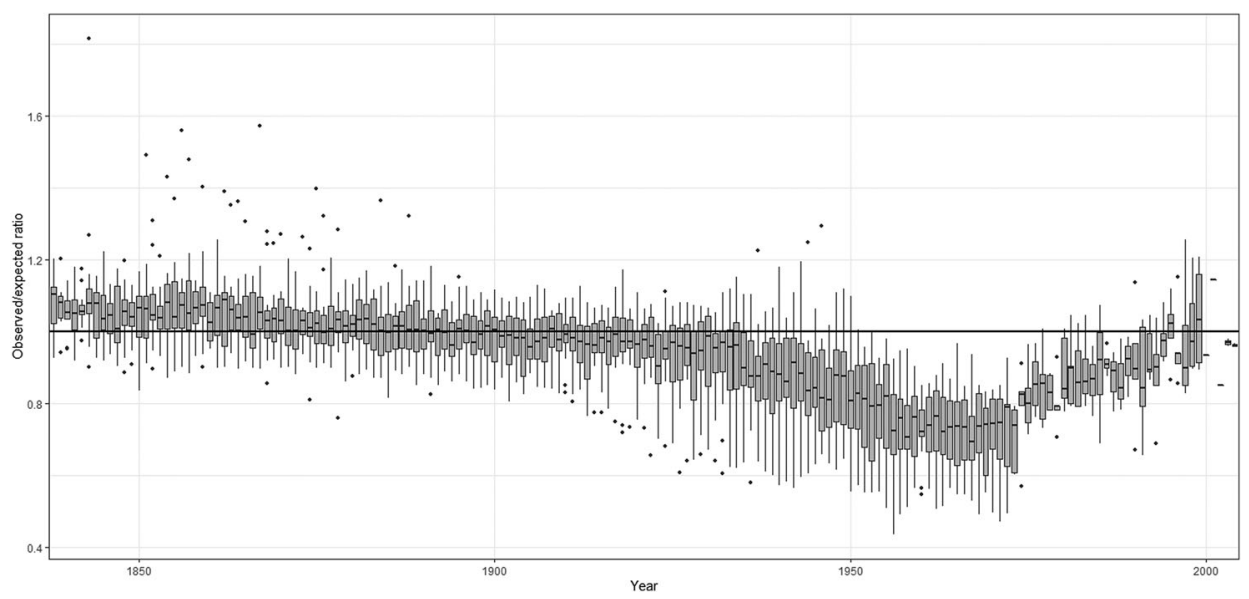

FigURE 3. Box-and-whisker plots of the observed/expected ratio for birth records containing any of the 26 alliterative two-letter combinations per year (for instance, both first and family names beginning with $A$ ).

explanation is the inclusion of data from Wales, in which Welsh names such as Dafydd are, unsurprisingly, disproportionately represented. If repeating the analysis with records from Wales omitted, these $19^{\text {th }}$ century outliers disappear (see supplementary material). The potential confounding effects of ethnic and regional grouping are discussed in more detail below.

The observed/expected ratio steadily declines throughout the $20^{\text {th }}$ century to the extent that by the I970s, alliterative names appear actively avoided, with ratios falling $<0.8$. When comparing the distributions of observed and expected counts $(n=\mathrm{I}$ 1029) for records made between $\mathrm{I} 900$ and I970, the difference is statistically significant (Kolmogorov-Smirnov $\left.p=2.4 \times 1 \mathrm{IO}^{-5}\right)$. There were a significantly lower number of records observed than expected (within the time period of I900-I970, the median number of observed and expected records per year was 877 and 1066, respectively), with a corresponding chi-squared test $p<2.2 \times \mathrm{IO}^{-16}$ (see Supplementary material Table 5).

From the I970s to the last year represented in the figure (2006), the observed/ expected ratios rise again to approach I. This suggests that towards the end of the $20^{\text {th }}$ century the trend to avoid alliterative naming has been reversed and that, relative to previous years, alliterative names had greater appeal (for data recorded from 1970 onwards, $n=\mathrm{I} 52$, Kolmogorov-Smirnov $\left.p=3.6 \times \mathrm{IO}^{-3}\right)$. It is important to note that compared to historical records there are relatively few contemporary records in this dataset (see Supplementary material Table 4). As such, it is unclear as to whether the observed number of alliterative records will consistently exceed the expected number - which Figure 3 suggests but does not show - or whether early $2 \mathrm{I}^{\text {st }}$ century alliterative naming patterns will resemble those observed of the $19^{\text {th }}$ century. Finally, the division of this dataset into three broad time periods is essentially arbitrary. It is therefore important to note that the difference in observed and expected distributions, when considering the 
entire dataset, remains statistically significant $(n=2087$, Kolmogorov-Smirnov $p=7.8 \times$ I04). In absolute terms, and consistent with the mid- $20^{\text {th }}$ century aversion to alliterative naming, there was also a significantly lower number of observed than expected alliterative records per year across the entire dataset (median records 6804 and 6933, respectively; chi-squared test $p<\mathbf{2 . 2} \times 10^{-16}$ ).

\section{Discussion}

This study provides an overview of three patterns of alliterative name use observed in England from the $19^{\text {th }}$ century to the present day: 'ambivalence' (from the $19^{\text {th }}$ to early $20^{\text {th }}$ centuries, where the observed numbers of alliterative names do not significantly differ from the expected), 'avoidance' (the early to mid-20 ${ }^{\text {th }}$ century, where the observed number is lower than expected) and 'appeal' (the mid-20 ${ }^{\text {th }}$ century to the present day, where the 'avoidance' trend is reversed ${ }^{5}$ ). A more nuanced exploration of these patterns would necessitate addressing several limitations of this dataset and the analysis.

Firstly, in order to parse the large volume of data comprising this study, the simplifying assumption was made that the majority of records use only one language, English. Alliteration was also defined pragmatically, as the repetition of initial characters in both the forename and surname. This definition was limited to the 26 characters of the English alphabet and so the analysis neither accommodates diacritics or other characters of non-English origin nor, given the focus on initial characters, digraphs such as the Welsh $f f$ or $l l$. A clear limitation of this study is that in reality the dataset comprises names from an unknown number of languages. As such, an unknown number of records are expected using other alphabets found throughout the British Isles and beyond, including but not limited to Welsh (with its 29 letter alphabet), Manx (24 letters), and Scots Gaelic ( 8 letters). However, as languages are abundant within certain geographical regions, but not necessarily exclusive to them, the data cannot easily be partitioned into language-specific subsets. The Anglocentric definition of alliteration also assumes that identical characters correspond to identical sounds, which simultaneously discards names that are alliterative only when spoken, such as George Jones, and includes names that are only alliterative in print, such as George Grey. An assumption of this study is that this does not meaningfully alter the observed trends.

Secondly, when calculating the expected numbers of alliterative records per year, the assumption was made that any given surname could, in principle, be paired with any given forename although in a diverse population, this would overestimate the expected numbers. In reality, forenames and surnames co-occur on the basis of ethnocultural origin. Predicting ethnicity from name data is a non-trivial problem (Kandt and Longley 2018; Fiscella and Fremont 2006; Sood and Laohaprapanon 2018) that was not attempted here. A consequence for this study is that the observed/expected ratios will be underestimated. To control for this, we could repeat the analysis after restricting data to names most commonly 
associated with a self-reported 'white British' ethnicity, considered to be the ethnic majority within the dataset. However, this is complicated by the fact that forenames and surnames with a 'white British' association are not easy to ascertain. We could assume instead that the top 20 surnames, which are registered in every year of the dataset, are reasonably strong correlates of ethnic majority individuals. This is the same approach taken by Jones et al. (2004) who, in a study of US American names, controlled for ethnic confounds by restricting analysis to the surnames Smith, Johnson, Williams, Jones, and Brown, considering these to be "common European American," and ethnically white, names. This approach is pragmatic but flawed: (Simonsohn 20II) notes that in the US census of 2000 , only $62 \%$ of individuals with these surnames reported their ethnicity as white. We can assume the UK data will be similarly confounded and that attempts to control for this using surnames will, at best, be crude.

Other approaches to reducing heterogeneity in the data are to repeat the analysis having restricted data only to England, to Wales, or to one English county, assuming the regional distributions of surnames may also exert an influence. Of the total number of records, $45 \%$ are sourced from the county of Lancashire, in north-west England, with the most spatially-restricted subset of records ( $2 \%$ of the total) $\mathrm{lim}$ ited to one south-western city, Bath (Supplementary material Table I). In all, 6\% of the records are sourced from Wales. Repeating the analysis using all five subsets (data only from a subset of surnames, only from England, from Wales, from Lancashire, or from Bath) results in no observable difference to the trends illustrated in Figure 3 (see Supplementary material Tables 6 through II). Note that with the Wales, surname-subset, and Lancashire data, the 'ambivalence' and 'avoidance' patterns could be observed, but not the 'appeal'. This was because data was only available up to the years I950, I97I, and I982, respectively. The Bath subset, being the smallest, could only be visualised when requiring no minimum number of records for each letter combination. While the data is noisier as a consequence, the ambivalence/avoidance/appeal pattern can still be seen (Supplementary material Table 9).

Thirdly, there is a relative paucity of contemporary records in this dataset. The avoidance of alliterative naming throughout the $20^{\text {th }}$ century is supported by $>$ I00,000 records per year until the I950s (see Supplementary material Table 2). However, as there are fewer records in subsequent years, less clear is the extent to which alliterative naming has become more prevalent since. In absolute terms, a small number of records exacerbates the difficulty of studying alliterative names as, by their nature, only a small proportion of records (approximately $4-5 \%$ ) contain them. We are further limited by the need to have both forename and surname data for the same individual; however, for privacy reasons this information may not be easily accessible.

Two related questions are suggested by the results of this study: what underlies the decline in popularity of alliterative names throughout at least the first half of the $20^{\text {th }}$ century, and what underlies their relative contemporary appeal? With regard to the former, an explanation may be suggested on the basis of a 
study of Swedish personal names in which alliteration was found actively avoided. (Hagåsen 20II) collated the first and last elements of the $3000 \mathrm{com}-$ monest Swedish dithematic surnames: those comprising two differentiallystressed lexemes, such as Haglund. The permillages were then calculated: the number of occurrences, per thousand, of the last element in relation to the first. It was found that alliteration between the two elements was substantially underrepresented in the set of extant names, with the tendency to avoid it strongest when assonance was also present. These findings were related to an "aspiration to dignity in name formation" which alliteration (and rhyme) could undermine:

If the purpose of alliteration and rhyme is to provide a feast for the ear in poetry recitation and give the impression of playfulness and verve in speech, such effects have apparently not been very desirable in the Swedish name categories discussed here [...] the rejection of rhyming elements should certainly be ascribed to people's anxiety about forming names that might make a conspicuous and even ridiculous impression (Hagåsen 2011, I06).

We can speculate that alliterative naming makes a similar impression in English, albeit on the basis that Swedish and English share commonalities, both being Germanic languages. This conspicuous impression would not necessarily apply to other languages represented in the dataset. This Swedish study focussed on surnames, however, which have greater generational stability than forenames. The long-term avoidance of alliterative surnames suggests that negative perceptions of alliteration are consistent. This was not the case with our data as the avoidance of alliterative naming appeared to be a uniquely $20^{\text {th }}$ century phenomenon. The reason for this is unclear. We can speculate that a change in the prevalence of alliterative names in the cultural milieu, and the context in which they were used, has shaped perception at that time. Given the period in which alliterative names declined in popularity, we can speculate that this was concomitant with the spread of new forms of media, and its dissemination of new types of name. A fuller exploration of this hypothesis is beyond the scope of this study. However, it is worth noting that early to mid-20 th century Anglophone sources have documented an abundance of alliterative names in a variety of contemporary contexts, including comic strip characters (Tysell I934, I935), advertising copy (Coard I959), and the ring names of boxers (McCartney I938).

Might the conspicuity of alliteration, and the impression this makes, also relate to the contemporary appeal of alliterative naming? This would be consistent with the contemporary preference for 'standing out' through the choice of an uncommon name. This point has been discussed by numerous authors (e.g., Twenge, Abebe, and Campbell 20I0; Twenge, Dawson, and Campbell 2016). Alternatively, any negative associations with alliterative names may simply have been normalised towards the end of the $20^{\text {th }}$ century, and no longer hold by the present day. For much of the time period recorded in this study, the dominant attitude towards alliterative naming appears to be 'ambivalence'. Future research 
could focus on parental attitudes towards alliteration and whether any distinctiveness perceived of an alliterative name influences the choice. The effect an alliterative name has on the individual is similarly unknown although would presumably be limited only to those circumstances where the full name is used, and the alliteration actually apparent.

There is a wide body of anthroponomastic attitudinal research documenting the perceptions associated with names, particularly those considered (un)common, (un)familiar, or 'other' (e.g., Carpusor and Loges 2006; Hilliar and Kemp 2008), although comparatively little research on the impression made by an alliterative name. Within an Anglocentric context, relatively uncommon forenames have been positively associated with perceptions of academic ability (Erwin I999), professional competence (Sadowski, Wheeler, and Cash I983) and artistic creativity (Lebuda and Karwowski 20I3), and so, in some contexts, may have a positive psychological effect (Zweigenhaft I983), a possible explanation for their contemporary popularity. Other studies, however, have reported more negative connotations, across a range of attributes, for uncommon - or perceptibly less familiar - forenames (Levine and Willis I994; Karlin and Bell I995; Joubert I993) and surnames (Colman, Sluckin, and Hargreaves I98I). There are fewer associations with alliterative names, although alliteration has previously been identified as a factor in mate selection - individuals whose first names (Kopelman and Lang I985) or nicknames (Brandwein et al. 2018) began with the same letter were found more likely to marry than random expectation (although these correlations may be spurious (Simonsohn 20II)). It would be of particular interest to explore the (possibly attractive) impression made by alliterative names in other circumstances - such as job applications - where the use of both first and family names is hard to avoid.

In summary, this study identifies three distinct patterns of alliterative baby naming from $19^{\text {th }}$ century England to the present day. The data suggests that towards the mid $-20^{\text {th }}$ century, there has been a change in perceptions of the impression made by an alliterative name. This is an underexplored phenomenon that may offer new insight into a period in which cultural norms around naming were in flux.

\section{Notes}

I. While near-complete, UK and US name datasets are publicly available they contain individual forenames and no surnames. For instance, a census dataset collected by the United States Social Security Administration (https://www.ssa.gov/OACT/babynames/ names.zip) represents first name usage per year, from I 880 onwards, of a complete survey of all US Americans with social security numbers. A comparable UK dataset is available from the Office for National Statistics, representing a record of all live births from I996 to 2016 (https://www.ons. gov.uk/file?uri=/peoplepopulationand community/birthsdeathsandmarriages/ livebirths/datasets/babynamesengland andwalesbabynamesstatisticsgirls/2016/ a dhocallbabynames I 996 to 20 I 6.xls). Data are restricted to forenames registered at least five (US) or two (UK) times per year.

2. The website hosting the UK local BMD data, www.ukbmd.org.uk, is operated by Weston Technologies Ltd (Crewe, Cheshire, UK). This company is the owner or licenseholder of the intellectual property 
constituting the birth records. This data is used here pursuant to section 29A of the UK Copyright, Designs and Patents Act I988, where a copyright exception permits copies to be made of lawfully accessible material in order to conduct text and data mining for non-commercial research.

3. All supplementary material for this paper, comprising II tables and 5 figures, is freely available via the Oxford Research Archive at https://doi.org/I0.5287/ bodleian:4JYXKrzzg.

4. The greater diversity of female names belies the ease with which a name can be inferred as female. In English, there are a small number of predominantly female-name endings, consistent with a patriarchal tradition of higher male status; these endings are preferentially avoided in maletyped names (Barry and Harper 2000/
2005). The preferential maintenance of a smaller number of traditionally male-typed names (for instance, when naming children for ancestors) would also be consistent with patriarchal tradition, and contribute to why the number of male names is smaller than female names.

5. It is worth clarifying that this use of the word 'appeal' refers to a trend, not an observed/expected ratio: the appeal of alliterative names (towards the end of the $20^{\text {th }}$ century) is relative to a period in which alliterative names were preferentially avoided (the mid $20^{\text {th }}$ century). As shown in Figure 3, this does not mean that the observed number of alliterative records is necessarily significantly greater than expected in a given year.

\section{Disclosure statement}

No potential conflict of interest was reported by the author.

\section{ORCID}

\section{Stephen J. Bush (D) http://orcid.org/o0oo-oooI-934I-2562}

\section{References}

Barry, Herbert, and Aylene S. Harper. 2000. "Three Last Letters Identify Most Female First Names." Psychological Reports 87, no. I: 48-54.

Barry, Herbert, and Aylene S. Harper. 2005. "The Majority of Female First Names Ended in a or E throughout the Twentieth Century." In Gender Roles, edited by Janice W. Lee, II7-I43. Hauppauge, NY: Nova Science Publishers, Inc.

Boers, Frank, and Seth Lindstromberg. 2005. "Finding Ways to Make Phrase-Learning Feasible: The Mnemonic Effect of Alliteration." System 33, no. 2: 225-238.

Boers, Frank, Seth Lindstromberg, and June Eyckmans. 20I4. "Is Alliteration Mnemonic without Awareness-Raising?" Language Awareness 23, no. 4: 29I-303.

Brandwein, Ann Cohen, Richard E. Kopelman, Steven Shin, and Janet L. Rovenpor. 2018. "Alliteration in Mate Selection: Does Barbara Still Marry Barry?” Society 5 5, no. 4: 34I-343.

Bush, Stephen J. 2019. "Re-Using the Names of Newborns: Symbolic Reincarnation in an Age of Infant Mortality." Names 67, no. 2: I00-I I 2.

Bush, Stephen J., Anna Powell-Smith, and Tom C. Freeman. 2018. "Network Analysis of the Social and Demographic Influences on Name Choice within the UK (I838-2016).” PLoS One I3, no. Iо: eo205759.

Cai, H., X. Zou, Y. Feng, Y. Liu, and Y. Jing. 20I 8. "Increasing Need for Uniqueness in Contemporary China: Empirical Evidence." Frontiers in Psychology 9: 554.

Carpusor, Adrian G., and William E. Loges. 2006. "Rental Discrimination and Ethnicity in Names." Journal of Applied Social Psychology 36, no. 4: 934-952.

Coard, Robert L. I959. "Wide-Ranging Alliteration.” Peabody Journal of Education 37, no. I: 29-35.

Colman, Andrew M., Wladyslaw Sluckin, and David J. Hargreaves. I98I. "The Effect of Familiarity on Preferences for Surnames." British Journal of Psychology 72, no. 3: 363-369. 
Erwin, Philip G. I999. "Attractiveness of First Names and Academic Achievement." The Journal of Psychology I33, no. 6: 61 7-620.

Fiscella, Kevin, and Allen M. Fremont. 2006. "Use of Geocoding and Surname Analysis to Estimate Race and Ethnicity." Health Services Research 4I, no. 4 Pt I: I482-I 500.

Gerhards, Jürgen, and Rolf Hackenbroch. 2000. "Trends and Causes of Cultural Modernization: An Empirical Study of First Names." International Sociology I 5, no. 3: 50I-53 I.

Hagåsen, Lennart. 20II. "Restrictions on Alliteration and Rhyme in Contemporary Swedish Personal Names with an Old Germanic Retrospect." In Alliteration in Culture, edited by Jonathan Roper, 93-I08. London: Palgrave Macmillan UK.

Hilliar, K. F., and R. I. Kemp. 2008. "Barack Obama or Barry Dunham? The Appearance of Multiracial Faces Is Affected by the Names Assigned to Them." Perception 37, no. I0: I605-I608.

Jones, J. T., B. W. Pelham, M. Carvallo, and M. C. Mirenberg. 2004. "How Do I Love Thee? Let Me Count the Js: Implicit Egotism and Interpersonal Attraction." Journal of Personality and Social Psychology 87, no. 5: 665-683.

Joubert, Charles E. I993. "Personal Names as a Psychological Variable." Psychological Reports 73, no. 3_suppl: I I23-I I 45 .

Kandt, Jens, and Paul A. Longley. 20I8. "Ethnicity Estimation Using Family Naming Practices." PLoS One I3, no. 8: eo20I774.

Kangro, Robert. 2006. "Internal Alliteration in North Germanic Dithematic Personal Names." Nowele 49, no. I: II3-I 26.

Karlin, Nancy J., and Paul A. Bell. 1995. "Assessing Commonality and Favorability of First Names." Psychological Reports 77, no. I: 97-98.

Kopelman, Richard E., and Dorothy Lang. I985. "Alliteration in Mate Selection: Does Barbara Marry Barry?” Psychological Reports 56, no. 3: 79I-796.

Lea, R. Brooke, David N. Rapp, Andrew Elfenbein, Aaron D. Mitchel, and Russell Swinburne Romine. 2008. "Sweet Silent Thought: Alliteration and Resonance in Poetry Comprehension." Psychological Science I9, no. 7: 709-716.

Lebuda, Izabela, and Maciej Karwowski. 2013. "Tell Me Your Name and I'll Tell You How Creative Your Work Is: Author's Name and Gender as Factors Influencing Assessment of Products' Creativity in Four Different Domains." Creativity Research Journal 25, no. I: I37-I42.

Levine, Marci B., and Frank N. Willis. I994. "Public Reactions to Unusual Names." The Journal of Social Psychology I34, no. 5: 56I-568.

McCartney, Eugene S. 1938. "Alliteration on the Sports Page." American Speech I3, no. I: 30-34.

Ogihara, Y., H. Fujita, H. Tominaga, S. Ishigaki, T. Kashimoto, A. Takahashi, K. Toyohara, and Y. Uchida. 20I 5. "Are Common Names Becoming Less Common? The Rise in Uniqueness and Individualism in Japan." Frontiers in Psychology 6: I490.

$\mathrm{R}$ Core Team. 2019. R: A Language and Environment for Statistical Computing. Vienna, Austria: $\mathrm{R}$ Foundation for Statistical Computing.

Sadowski, Cyril J., Karen J. Wheeler, and Michele Cash. I983. "Unusual First Names and Achievement among Male Psychologists.” The Journal of Social Psychology I I9, no. 2: I8 I-I 85.

Simonsohn, Uri. 20II. "Spurious? Name Similarity Effects (Implicit Egotism) in Marriage, Job, and Moving Decisions." Journal of Personality and Social Psychology IOI, no. I: I-24.

Snyder, C. R., and H. L. Fromkin. I977. "Abnormality as a Positive Characteristic: The Development and Validation of a Scale Measuring Need for Uniqueness." Journal of Abnormal Psychology 86, no. 5: 5I 8-527. http://dx.doi.org/I0.1037/002 I-843X.86.5.5 I8.

Sood, Gaurav, and Suriyan Laohaprapanon. 2018. "Predicting Race and Ethnicity from the Sequence of Characters in a Name.” arXiv. Accessed May I7, 2020. https://arxiv.org/abs/I 805.02 I09.

Twenge, Jean M., Emodish M. Abebe, and W. Keith Campbell. 2010. "Fitting in or Standing out: Trends in American Parents' Choices for Children's Names, I880-2007." Social Psychological and Personality Science I, no. I: I9-25.

Twenge, Jean M., Lauren Dawson, and W. Keith Campbell. 20I6. "Still Standing out: Children's Names in the United States during the Great Recession and Correlations with Economic Indicators." Journal of Applied Social Psychology 46, no. I I: 663-670.

Tysell, Helen. 1934. "Character Names in the Comic Strips." American Speech 9, no. 2: I 5 8-160.

Tysell, Helen. I935. "The English of the Comic Cartoons." American Speech Io, no. I: 43-55.

Zweigenhaft, Richard L. I983. "Unusual First Names: A Positive Outlook.” Names 3 I, no. 4: 258-270. 


\section{Notes on contributor}

Stephen J. Bush has a PhD in evolutionary genomics from the University of Bath, was a postdoctoral research fellow at the Roslin Institute, University of Edinburgh, and is currently a bioinformatician at the University of Oxford. http://orcid.org/0000-000I-934I-2562.

Correspondence to: Stephen J. Bush, NDM Experimental Medicine, University of Oxford, Oxford, UK. Email: stephen.bush@ndm.ox.ac.uk 